\title{
Personalizing the design of computer-based instruction to enhance learning
}

\author{
Hitendra Pillay,* Wageeh Boles** and Leonard Raj* \\ *Centre for Cognitive Processes in Learning. Email: h.pillay@qutedu.au. \\ **School of Electrical and Electronic Systems Engineering, Queensland University of \\ Technology, Australia
}

This paper reports two studies designed to investigate the effect on learning outcomes of matching individuals' preferred cognitive styles to computer-based instructional (CBI) material. Study 1 considered the styles individually as Verbalizer, Imager, Wholist and Analytic. Study 2 considered the bi-dimensional nature of cognitive styles in order to assess the full ramification of cognitive styles on learning: Analytic/Imager, Analytid Verbalizer, Wholist/Imager and the Wholist/Verbalizer. The mix of images and text, the nature of the text material, use of advance organizers and proximity of information to facilitate meaningful connections between various pieces of information were some of the considerations in the design of the CBI material. In a quasi-experimental format, students' cognitive styles were analysed by Cognitive Style Analysis (CSA) software. On the basis of the CSA result, the system defaulted students to either matched or mismatched CBI material by alternating between the two formats. The instructional material had a learning and a test phase. Learning outcome was tested on recall, labelling, explanation and problem-solving tasks. Comparison of the matched and mismatched instruction did not indicate significant difference between the groups, but the consistently better performance by the matched group suggests potential for further investigations where the limitations cited in this paper are eliminated. The result did indicate a significant difference between the four cognitive styles with the Wholist/Verbalizer group performing better then all other cognitive styles. Analysing the difference between cognitive styles on individual test tasks indicated significant difference on recall, labelling and explanation, suggesting that certain test tasks may suit certain cognitive styles.

\section{Introduction}

The continued innovations in multimedia technology and powerful programming software ensure that computer-based instruction (CBI) will become an integral part of our teaching and learning process and a dominant educational delivery system in many parts of the world (Bork, 1991). Yet despite the popularity of CBI material, there is a gap in understanding of the relationship between multimedia and learning. Kozma (1994) argues 
that any understanding of the relationship between media and learning must be grounded in cognitive and social processes associated with knowledge construction. Due to a lack of understanding of the relationship between learning and multimedia, the incentive for developing CBI packages has been the innovative alternative in information technology for presenting instructional material rather than learning theories (Ambron and Hooper, 1990). Hence, Hedberg, Harper and Brown (1993) have called for a closer examination of ways in which information is accessed and processed in current learning packages as a basis for designing CBI packages for effective learning outcomes.

Many available CBI packages claim advantages such as providing increased accessibility, immediate feedback, interactive learning, and a more flexible learning environment. These considerations are often dealt with in a physical sense which does contribute to enhanced learning, but they fail to address cognitive aspects. For example, flexibility and learner control is seen as an option for the learner to select what and when to learn (Reeves, 1993). Such options do not allow for cognitive flexibility where individuals can choose instructional formats which are congruent with their preferred way of perceiving and processing information. Similarly, navigation within CBI is often not aligned to cognitive processes associated with making connections between the learning processes and the content, or concerned with the impact of different navigation systems on cognitive capacity and how it affects individuals' ability to access and process information (Hedberg et al, 1993). It is argued by Upitis (1990) and Farrow (1993) that many of these perceived benefits may in fact be better achieved through traditional material than contrived use of technology-based learning environments. Given the lack of sufficient research on the role of cognition and learning in the design of CBI material, there are two related issues that are of interest with respect to this paper. The first issue is the effect of individuals' preferred cognitive styles on learning; the second is concerned with cognitive load effects of reconciling CBI material that is incongruent with their preferred cognitive styles when learning.

\section{Learning and preferred cognitive styles}

Current literature on learning suggests that it is an active, constructive, cognitive and social process by which the learner strategically manages the available cognitive, physical and social resources to construct knowledge (Shuell, 1988). Such construction requires individuals to direct attention to relevant aspects of the given information and relate it to previous experiences and knowledge, that is, to transform the information. Individuals access and process information differently, so that the success of any transformation process may be enhanced by the opportunities individuals have to access and process information in their preferred styles.

Preferred cognitive style is an individual's characteristic and consistent approach to organizing and processing information. Keefe $(1979,4)$ defined cognitive style as 'characteristic cognitive, affective, and physiological behaviours that serve as relatively stable indicators of how learners perceive, interact with, and respond to the learning environment'. Cognitive style needs to be distinguished from cognitive strategies: a style is considered to be a fairly fixed characteristic of an individual, while strategies are methods of coping with information which may be incongruent with the individual's preferred style (Riding and Cheema, 1991). Cognitive styles have been investigated by many researchers, resulting in a myriad of theories and cognitive-style types. A comprehensive analysis of the 
various labels, descriptors, classifications, and methods of assessment by Riding and Cheema (1991) led to the formation of two principal cognitive style groups: the WholistAnalytic (WA) and the Verbal-Imagery (VI) dimensions. The WA continuum represents the manner in which individuals process information, either in whole or in parts; the VI dimension characterizes individuals who are inclined to represent information verbally or in mental images. The two dimensions are independent of each other in that the position of individuals on the WA dimension does not affect their position on the VI dimension. Individuals may have a single cognitive style or be bi-dimensional which is how the majority of people are. Bi-dimensional groups include Wholist/Verbalizer, Wholist/Imager, Analytic/Verbalizer and Analytic/Imager.

Evidence from research on the effect of cognitive styles on learning suggests that cognitivestyle characteristics such as perception and processing of information enhance learning outcomes (Rush and Moore, 1991; Riding and Sadler-Smith, 1992; Riding and Douglas, 1993; Riding and Caine, 1993). Although most of these studies were conducted using conventional instruction, it is plausible to assume that similar outcomes may eventuate when using CBI. The above studies argue that optimum learning outcomes are obtained when the instructional material can be transferred readily to learners' personal modes of representation. More specifically, studies investigating an individual's position on the Wholist-Analytic dimension have found that it affects reading performance (Riding and Mathias, 1991), learning from structured material (Riding and Sadler-Smith, 1992), and occupational stress (Borg and Riding, 1993).

Although individuals have preferred cognitive styles, they can use alternative styles by making a conscious choice (Riding and Dyer, 1980). For instance, imagery style is often used by Analytics to acquire a wholistic view where an image can be encompassing and a whole. In addition, Verbalizers can translate pictures into words or semantic representations, and Imagers can convert semantic information into mental pictures. Circumstances which force individuals to choose cognitive styles other than their habitual ones may require additional effort which may not assist in learning but may be necessary for reorganizing the given information. From a cognitive-load perspective (Sweller, 1989), it may be argued that the ability to direct additional effort to aspects essential for learning is determined by the availability of sufficient cognitive resources. Our limited cognitive resources, if directed to extraneous activities, leave insufficient resources available for learning to occur (Sweller, 1989; Halford, 1993; Pillay, 1997). Extraneous activities are often introduced because of poor instructional design, such as CBI material developed on experts' mental models. Such CBI material mimics the network of knowledge displayed by experts' memory systems (Jonassen, 1989). As such, it inhibits individuals from processing information in a manner familiar to them, and thus requires them to reorganize given information in a manner that is more readily accessible to them. Such extraneous processes are not necessary for learning but essential only because of the instructional format. Consequently, learners resort to employing strategies which are concerned with obtaining a solution rather than learning about the structure of the problem (Sweller, 1989). Understanding a problem structure and categorizing it are essential parts of learning (Chi et al, 1981). Matching instruction to preferred style frees up cognitive resources that can be directed to making links between information currently attended to, information from previous screens, and prior knowledge. 
The recognition of individual learning preferences is increasingly becoming an important consideration in the design and delivery of instruction (Dunn et al, 1985; Claxton and Murrell, 1987; Riding and Sadler-Smith, 1992). If individuals have their own habitual ways of perceiving, representing and structuring information for learning, then 'identifying a student's style and then providing instruction consistent with that style contributes to more effective learning' (Claxton and Murrell, 1987, 1). Even though there is a general acceptance by educators that students differ in how they perceive and process information, and although attempts to cater for this difference can be seen in the more traditional instruction, it has not gained the same recognition in the design of CBI material (Pillay and Wilss, 1996).

\section{Designing CBI to accommodate preferred cognitive styles}

There are two principal considerations in designing instruction to accommodate preferred cognitive styles: the manner in which the information is formatted to allow easy access to the issues presented, and how individuals process the given information.

The format involves the use of graphical images and/or verbal (text) information. This Verbal-Imagery mix may affect the modes in which individuals represent information during thinking. They may use mental images to represent given information or use verbal representations, as thoughts can be articulated in words or pictures (Riding and Calvey, 1993). Verbalizers prefer information presented as words or verbal associations, whereas Imagers represent information better with mental pictures of given information. The design of each CBI screen should reflect the preference of the cognitive style being catered for. Considerations include the ratio of text to graphics, the nature of the text information (very vivid narrative text would suit Imagers whereas a list of points would suit Verbalizers), and the nature of the information being presented. Procedural information is often serial and thus better presented in point form, whereas conceptual knowledge may require information from multiple sources. Similarly, the nature of images should be considered because images often are not complete in themselves and hence require additional information, often in text form, to make them meaningful. In determining the design composition, it must be noted that it is not a case of either/or in each of the above situations, but of emphasis.

Recent developments in information technology may help individuals construct realistic dynamic images by using simulated movements. Hidden details may be displayed by using overlays. Creative use of the technology, such as the use of layers to progressively build an image, can be an effective method for learning from images. Images that are poorly designed often require supplementary text information. Such images may not benefit the Imagers. Similarly, the formatting of text information can affect its benefit to Verbalizers. A number of options such as bullet points, narrative prose and voice-interactive systems may be utilized.

Accessibility is also influenced by the nature of subject content (Riding and Douglas, 1993). There are certain types of content that lend themselves more favourably to certain cognitive styles. Imagine learning architecture by reading text material only. The spatial nature of the subject content would force individuals to engage in imagery to fully appreciate the spatial concepts. In terms of content to be learned, Verbalizers cope better with understanding and 
recall from prose passages which may contain unfamiliar information than Imagers who learn best from passages with few unfamiliar terms and which are descriptive and illustrated (Riding and Mathias, 1991). Even the design of the menus has potential for catering to Imagers and Verbalizers. The use of icons may benefit the Imagers, whereas word commands may benefit the Verbalizers. Hence the design of optimum instructional material to cater for either the Verbalizer or the Imager can be very involved.

The second issue is how individuals process information. Wholists tend to organize information into loosely clustered wholes so as to construct an overall understanding of the given information. By contrast, Analytics tend to process information in clear-cut conceptual groupings, and often focus on one of these groupings at a time (Witkin et al, 1977). They have the schema to integrate and construct meaning by firstly understanding the various sub-groups, then combining them to obtain a big picture. Strengths for Wholists include their ability to see the big picture of a situation and therefore have a balanced view of the given information. However, if Wholists direct most of their cognitive resources to finding links between the various elements of the instruction, they may not have sufficient resources to learn the whole picture. The down side for Wholists is that they often find it difficult to separate situations into parts and become analytical. Analytics can decompose problems into separate parts and may quickly diagnose a problem, but they may not be able to develop a big picture of the problem, that is, synthesize information.

Ausubel (1960) recognized that some individuals need to have an overview to assist them in their learning. Consequently, he developed the use of advance organizers. Advance organizers can be images or text, but it is the manner in which the information is structured that assists the Wholist and Analytic to effectively process information. Satterly and Telfer (1979) provided evidence that the use of advanced organizers helped Wholists to develop a big picture of given information rather than having to engage in search and construction processes from unfamiliarly structured information. Such a procedure may not benefit the Analytic style person who seeks detailed and highly structured information to conceptualize (Riding and Calvey, 1981). For the Analytics, consideration must be given to how the information is broken down to spread it over a number of screens and finally pull it together as a unit of information. However, maintaining information from a number of screens can be cognitively demanding. Consideration must then be given to the complexity and amount of information that is spread over a number of screens or layers. Satterly and Telfer (1979) examined various advance organizers and found that a careful design may help different cognitive styles. They proposed three types of advance organizers: the linker, integrator and the analyser.

Liu and Reed (1994) argued that hypermedia-assisted instruction has the potential to accommodate requirements of different learning preferences. They found that learners chose different tools and learning aids when working in a hypermedia learning environment. Thus, structuring of information to suit different cognitive styles needs careful consideration in the instructional design of CBI material.

\section{Research design}

Since we know from the studies conducted by Riding and his colleagues that preferred cognitive styles exist, matching the style with the instructional format may enhance 
learning (Entwistle, 1981; Riding and Sadler-Smith, 1992). If students can access information in a format that matches their cognitive style, the need to reorganize in accordance with their preferred style prior to learning is not necessary. The elimination of this step in information processing presumably reduces the cognitive load imposed by the task and enhances performance (Sweller, 1989; Halford, 1993).

The two studies reported here were designed to investigate the effect of matching preferred cognitive styles to instructional format on learning outcomes. The first study involved a small sample and considered cognitive style as a single characteristic such as 'Wholist or Imager', rather than a bi-dimensional one where the style is a combination of preferred style for perceiving and processing information. Also, the first study tested learning outcomes after only a single treatment session, which can be limiting (Reeves, 1993).The encouraging result of the first study prompted the second one. A larger sample allowed reliable statistical analysis. In addition, consideration was given to bi-dimensional cognitive styles in order to establish the full impact of cognitive style which, as identified by Riding (1991), is a combination of both perception and processing preferences. Both studies adopted a quasi-experimental design involving four groups of students: Wholist/Imager, Wholist/Verbalizer, Analytic/Imager, Analytic/Verbalizer. Each group was presented with either matched or mismatched instructional material which was developed to cater for each of the four cognitive styles. This resulted in eight treatment groups. Some of the characteristics considered in the design of instructional formats were advance organizers, text-plus-diagrams versus text-plus-spreading information across a number of screens, descriptive prose versus bullet points of specific information, and integrated diagrams versus diagrams of discrete parts.

All students were assessed for their preferred cognitive style using the Cognitive'Style Assessment software (CSA). Details of the design and development of CSA can be found in Riding (1991). Cognitive-style assessment works on the basis of response times to a battery of statements which are categorized into subsets, and a ratio for each subset is calculated. The first subset measures the Verbal/Imager dimension by asking conceptual and appearance recognition questions. The other two subsets in the CSA assess the Wholist/Analytic dimension. The first of these two subsets involves judging overall similarity of complex geometrical shapes. The second subset requires a degree of disembedding of simple shapes within complex geometrical figures. A detailed discussion of the rationale for CSA design can be found in Riding and Cheema (1991) and Riding and Douglas (1993). Figure 1 illustrates the organization of the experiments.

\section{Study 1}

\section{Sample}

Seventy-one students from a second-year nursing course at Queensland University of Technology participated in the study. Students who were defaulted to mismatched Imager instruction did not complete the tasks and were excluded from the analysis. The sample when distributed into the eight groups resulted in very small numbers of students in each group, hence the data is discussed qualitatively.

\section{Material}

The topic 'Compartment Syndrome' from the second-year nursing programme was used 


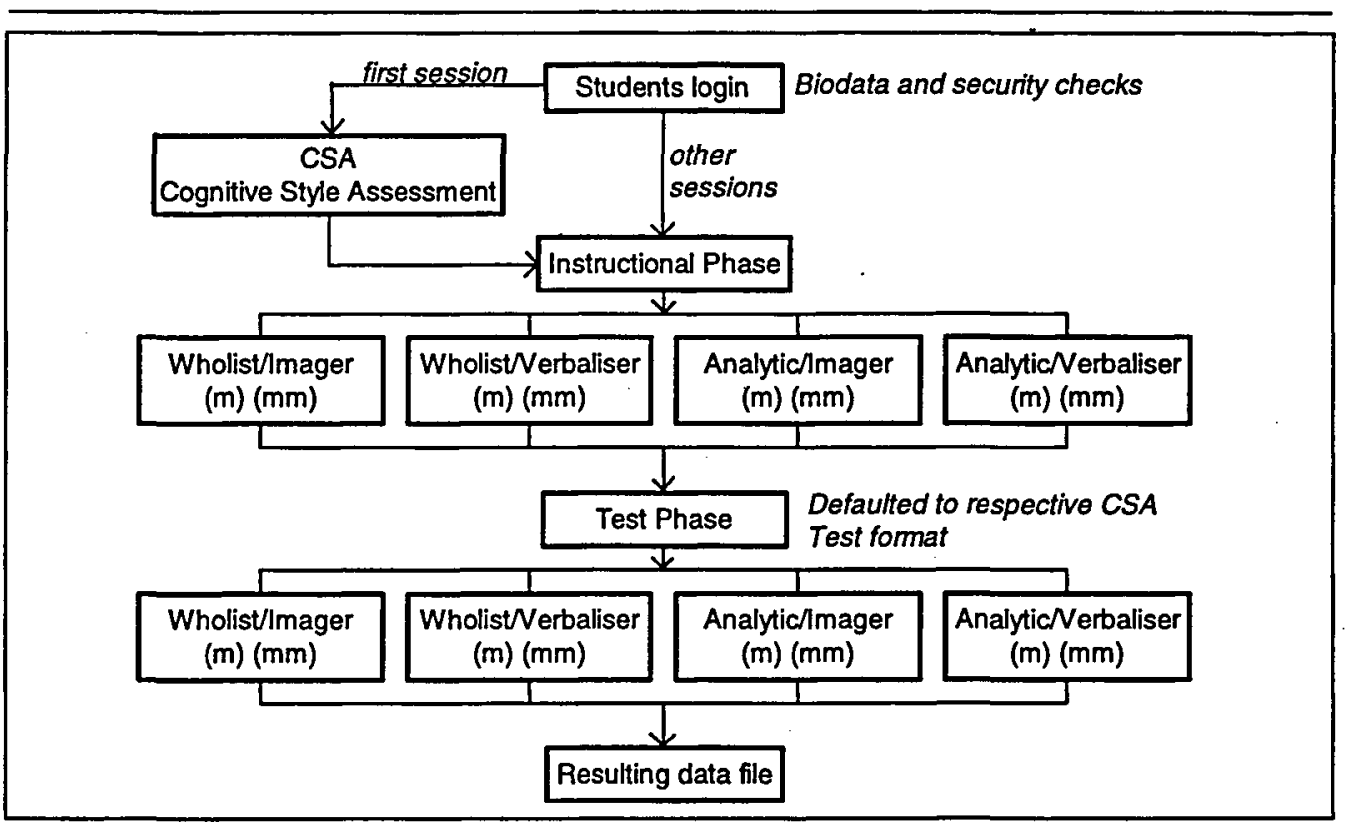

Figure 1: Organization of the experiments ( $m=$ matched cognitive style; $m m=$ mismatched cognitive style)

for the study. The topic was new to the students, so interference from prior knowledge was not a concern. The content material was analysed to determine the optimum structure for each of the four cognitive styles. The mismatched instruction was the style on the opposite end of the continuum. For example, the mismatched instruction for a Wholist style would be Analytic-style instruction. All instructional material had the same subject content but different formats. ToolBook authoring software was used to develop the instructional material, which was loaded on the network in an undergraduate computer laboratory.

Differences in design of the instructional materials for the four cognitive styles is apparent. The 'linker' advance organizer for the Wholist lesson contained information about the entire lesson, while the 'analytic' advance organizer for the analytic lesson was fragmented and contained information relating to specific parts of the lesson. The wholist screen contained more than just this section of information as it also moved onto the next part, the neurovascular assessment, thus allowing students in this preferred cognitive style to develop a big picture of the given information.

The 'imager' advance organizer was the only one that included a graphic depiction of various parts in the Compartment Syndrome topic, while Verbalizers were presented with text information in their advance organizer. Because content material involved understanding spatial location and relationships with adjacent components, diagrams were contained in all instructional formats except that of the Verbalizer. Thus it was necessary to make a distinction between the groups regarding the inclusion of diagrams. Wholists received a complete presentation of the components of a compartment, a diagram showing the compartments and what compartment syndrome is, as well as information regarding the location of compartments. Analytics were presented with three separate screens containing 
the same information which had graphical depictions, but these were of the separate components of a compartment rather than the overall view of a compartment which the Wholist lesson contained. Verbalizers were presented with the information in text form only, while Imagers had a single diagram that featured prominently in this section. Thus consideration of the requirements of each cognitive style was clearly evident in each lesson.

The test items were made up of seven recall-type questions based on statements requiring a true or false response, listing specific terminology, and multiple-choice questions. There were two explanation questions which required synthesis of details relating to the components of a compartment. For the problem-solving task, students were presented with a description of a situation involving compartment syndrome, and were asked to determine what manifestations of compartment syndrome might be evident and to outline procedures for further assessment of the situation. There was only one problem-solving type question. All marking and scoring of the test task was done in consultation with a nursing lecturer.

\section{CSA classifications}

Preferred cognitive style was calculated on the basis of the individual's highest cognitive style ratios from the two dimensions Wholist/Analytic and Verbalizer/Imager. This was determined by finding the central point for the Wholist/Analytic ratio which was 1.19, and the Verbalizer/Imager ratio which was 1.04. Students scoring higher than 1.19 on the Wholist/Analytic dimension were classified as Analytics, and those scoring less than 1.19 as Wholists. Similarly for the Verbalizer/Imager ratio: greater than 1.04 were classified as Imagers, and less than 1.04 as Verbalizers. The intermediate group stipulated by Riding (1991) was not considered mainly because of the small sample size. Using these subdivisions, a student with a Wholist/Analytic ratio of 0.91 and a Verbalizer/Imager ratio of 1.29 would have a preferred cognitive style of Wholist/Imager. However the stronger ratio for this student is 1.29 which is in the Verbalizer/Imager dimension. As this is greater than the central point (1.04), the preferred cognitive style is Imager.

\section{Procedure}

Students were tested during their normal tutorial times. They were informed about the process of working through the CSA. This was followed by the lesson, and they were then asked to $\log$ on. At the $\log$-on screen they entered their identification number, age, and gender. Having completed this, they worked through the CSA, which took approximately 15 minutes, and depending on their CSA result students were defaulted, alternating between matched and mismatched instructional material. They had no control over the choice of instructional material. Students studied the lesson, taking as long as they needed, then proceeded to the test phase. Once in the test phase, they could not return to the instructional material. The whole process took approximately 45 minutes per student.

The matched and mismatched groups for each cognitive style were compared on the following performance measures: percentage correct on recall questions, sophistication of explanations and successful problem-solving skills. A comparison of the overall performance of the matched and mismatched cognitive styles groups was also made.

\section{Results and discussion}

A comparison of performance of the matched and mismatched instructional groups on all test tasks, and for each of the four cognitive styles, is summarized in Table 1. The result 
indicates that when Wholists and Analytics received matched instruction, they performed better than when these groups were presented with mismatched instruction. However, in the case of the Verbalizers and the Imagers, the results did not support the use of matched instructional material. The mismatched Verbalizer group performed better in two of the three test tasks. Since the Imager group did not have any students presented with the mismatched instructional material, it was not possible to make any comparison.

\begin{tabular}{|c|c|c|c|c|c|c|c|c|c|c|}
\hline \multicolumn{9}{|c|}{ Individual cognitive styles } & \multicolumn{2}{|c|}{$\begin{array}{c}\text { Combined } \\
\text { cognitive } \\
\text { styles }\end{array}$} \\
\hline $\mathrm{n}=$ & $\begin{array}{c}m \\
g\end{array}$ & $\underset{9}{\mathrm{~mm}}$ & $\begin{array}{l}m \\
14\end{array}$ & $\begin{array}{c}\mathrm{mm} \\
10\end{array}$ & $\begin{array}{l}m \\
12\end{array}$ & $\begin{array}{c}\mathrm{mm} \\
10\end{array}$ & $\begin{array}{c}m \\
5\end{array}$ & $\stackrel{\mathrm{mm}}{0^{*}}$ & $\begin{array}{l}m \\
40\end{array}$ & $\begin{array}{c}\mathrm{mm} \\
29\end{array}$ \\
\hline \multicolumn{9}{|c|}{$\begin{array}{l}\text { Percentage correct on individual tasks } \\
\text { Test tosks }\end{array}$} & & \\
\hline $\begin{array}{l}\text { Recall } \\
\text { Explanation } \\
\text { Problem- }\end{array}$ & $\begin{array}{l}71 \\
100\end{array}$ & $\begin{array}{l}66 \\
66\end{array}$ & $\begin{array}{l}74 \\
71\end{array}$ & $\begin{array}{l}68 \\
20\end{array}$ & $\begin{array}{l}93 \\
65\end{array}$ & $\begin{array}{l}57 \\
43\end{array}$ & $\begin{array}{l}68 \\
25\end{array}$ & - & $\begin{array}{l}71 \\
64\end{array}$ & $\begin{array}{l}66 \\
50\end{array}$ \\
\hline solving & 33 & 30 & 53 & 17 & 55 & 34 & 58 & - & 43 & 33 \\
\hline \multicolumn{9}{|c|}{ Percentage correct on all three tasks } & 66 & 62 \\
\hline
\end{tabular}

Table 1: Comparison of matched and mismatched instructional formats on performance by test tosks and by cognitive styles $(m=$ matched; $m m=$ mismatched)

In light of the small sample size for each cognitive style, Table 1 has been collapsed to show the total effect of matched and mismatched instructional material on performance. A comparison of the total sample revealed that the matched group achieved a higher percentage of correct responses for each task-type than the mismatched group. It may be plausible to suggest that a trend appears to exist when CBI material is matched to individuals' preferred cognitive styles as students performed better (66 per cent correct) than those who received mismatched instruction ( 62 per cent). This concurs with the argument presented by Claxton and Murrell (1987) using conventional instruction, that learning can be enhanced by matching the instruction to individuals' preferred cognitive styles.

The better performance by the mismatched Verbalizers (who received an Imager lesson) may be due to variance caused by the type of information. Riding and Douglas (1993) have argued that verbal descriptive information which is easier to visualize can be recalled easily by Imagers. For example, to appreciate the way in which increased pressure can affect different parts of the human anatomy, cross-sectional images illustrating the spatial location of muscles, blood vessels and bones are needed. It is probably easier to imagine the cross-sectional images than to remember a long list of textual information. Thus the nature of subject matter may also influence the manner in which individuals process information. In the case of the Verbalizer group in this study, it is plausible to suggest that the nature of the information favoured Imager style, and therefore the mismatched group 
performed better. Support for the above contention has also been raised by Riding and Caine (1993).

The other interesting finding was the response to each test task. The size of the difference in performance between matched and mismatched groups was 14 per cent on the explanation task, followed by 10 per cent on problem solving, and finally 2 per cent on recall problems. This suggests that presenting information matched to cognitive styles may benefit certain types of tasks more than others. However, further studies need to undertaken to investigate the interaction between the task types and cognitive styles, and in terms of CBI design, further work with a larger sample.

\section{Study 2}

This study aimed at refining the processes used in Study 1 and obtaining a large enough sample to allow statistical analysis. The individual cognitive style in Study 1 was determined on the basis of the strongest preferences out of the four styles. This was simplistic because we know that both cognitive style dimensions are essential to fully appreciate the effect of cognitive styles on learning outcomes. Furthermore, the argument that a single session is not sufficient treatment to make any conclusive statement about the results (Reeves, 1993) prompted the design of the second study to include four sessions over four weeks. This would provide learners with sufficient time to respond meaningfully to the treatments which in turn would allow more reliable conclusions to be drawn.

Study 2 also adopted a quasi-experimental design involving four groups Wholist/ Verbalizer, Wholist/Imager, Analytic/Imager and Analytic/Verbalizer. These groups were presented with instructional material that either matched or mismatched their preferred cognitive style, making up eight treatment groups. The mismatched group were presented with their opposite cognitive style. For example, the opposite cognitive style for an Analytic/Verbalizer is Wholist/Imager. The instructional materials were developed in accordance with Riding's (1991) four cognitive styles. Characteristics considered in the design of instructional materials included advance organizers, text-plus-diagram versus text-plus-text, integrated diagrams versus diagrams of discrete parts, and descriptive prose versus bullet points of specific points.

\section{CSA classification}

Each student's preferred cognitive style was determined by the CSA software developed by Riding (1991) in order to obtain a ratio for the Wholist/Analytic and Verbalizer/Imager dimensions. On the Wholist/Analytic continuum a score equal to or greater than 1.35 was considered as Wholist, and a score of less than or equal to 1.03 as Analytic, with those falling in between 1.03 and 1.35 as intermediate. On the Verbalizer/Imager continuum, Verbalizers were equal to or less than 0.99 , and Imagers equal to or more than 1.09 . The intermediate groups are those that cannot be definitely classified into one of the four bidimensional cognitive styles and were not included in the study.

In accordance with the literature, it was hypothesized that students who received mismatched instruction would engage in extraneous search and reorganization processes resulting in poorer performance. Students' overall performance, and performance on the four individual test tasks for matched and mismatched instructional material, were compared. The total time taken to accomplish the tasks was also recorded for comparison. 
The second analysis was designed to investigate whether the nature of the subject content favoured any particular cognitive style (see Riding and Douglas, 1993). The final analysis investigated whether there was any relationship between the nature of the test tasks and cognitive styles.

\section{Sample}

A hundred and thirty-four undergraduate students enrolled in the Digital Communications course used for the study. The sample sizes reported include only those students who had completed the task fully. Some students did not attend all CBI sessions. The students were allocated to four groups according to their preferred cognitive styles: Wholist/Imager, Wholist/Verbalizer, Analytic/Imager and Analytic/Verbalizer.

\section{Material}

Computer-based instructions, corresponding to each of the four cognitive learning styles were developed for four specific topics: Synchronisation, Multiplexing and Multiple Access, Spread-Spectrum Techniques and Layered Protocols. One topic was presented each week over a four-week period. All instructional formats on each topic had the same subject content, but varied in presentation styles. For example, Wholist/Imagers received a complete presentation of the different configurations of the Multiple Access Algorithm (MAA), a comprehensive diagram, and some text information regarding the functions of the various components. Analytic/Imagers were presented with three separate screens containing the same information which also included diagrammatic depictions, but they were presented as separate aspects of the MAA system rather than the overall integrated view which was the format of the Wholist/Imager lesson. Thus students viewed a step-bystep, rather than a complete piece of information. The Wholist/Verbalizers and Analytic/Verbalizers, because they represent information in words during thinking, were presented with text containing the equivalent information. The nature of the text information also varied. It was presented either as descriptive prose or just bullet points. Descriptive instruction allows individuals to construct whole pictures whereas bullet points present details of specific points. Thus consideration of the requirements of each cognitive style is clearly evident in each lesson. Again, the authoring software was ToolBook.

The instructional material had a learning and a test phase. The learning phase consisted of an average of 25 screens of instructional material which students could move through backward and forward as they wished. The test phase consisted of tasks in recall, labelling, explanation and problem solving. Scores on each task, as well as the time taken for the learning and test phases were recorded. Recall consisted of five questions in each session, and it required students to recall the words which linked individual parts to overall concepts. The labelling task required students to fill in missing blanks on a given diagram; each session had five missing items which the students had to fill in. Explanation was a single question in each session. It required students to recall explanatory type of information. Problem solving was also a single question in each session; a hypothetical scenario was presented to students, and they had to analyse the given situation, and design and compute a solution.

The CSA programme and the instructional material were installed on the university network so that five computer laboratories could be used simultaneously to conduct the experiment. The test data and the time taken to complete the task were recorded each week 
and stored on a secure database within the university network system which is inaccessible to students.

\section{Procedure}

The procedure was similar to that of Study 1. Students were tested during their normal lecture times which are typically three-hour sessions. After a two-hour lecture, students were asked to study the remainder of the subject content via CBI. They were informed about the process of working through the CSA, followed by the lesson and the test tasks. Students were tested in five computer labs, all at the same time. The instructor supervised them, and instructed them not to cheat or look at information on other screens. Following the introduction, students were asked to $\log$ on to the system. At the log-on screen they entered their identification number, age, and gender. On entering their ID number during the first session, they were presented with the CSA software to measure their preferred cognitive style. The CSA took approximately 15 minutes, and depending on the result students were defaulted to their respective instructional material. Students' CSA results were saved in a file with their ID numbers, thus for all subsequent sessions the computer identified their preferred styles from their ID numbers and logged them on to the same cognitive-style instructional formats. The computer was programmed to allocate students in each cognitive style group by alternating them between matched and mismatched instructional material, thus giving no control to students on choice of instructional material. Students studied the lesson, taking as long as they needed, navigating backward and forward. When they were satisfied with their learning, they proceeded to the test phase. Once they had exited the test phase, they could not return to the instructional material. Responses to test items were recorded for each student and for each sub-task. The whole process took approximately 70 minutes per session. Students had to participate in four sessions, one every week over four weeks.

A two-factor non-orthogonal design using an analysis of unweighted means was used to analyse the data (Keppel, 1991). This analysis was necessary due to the presence of unequal sample sizes.

\section{Results}

Students' scores on test tasks for matched and mismatched cognitive styles groups were compared (see Table 2). There was no significant difference between the two groups on total scores: $F(1,119)=2.795, p<.05$. Comparing scores for matched and mismatched groups on individual sub-tasks also revealed no significant difference. However, the mean score of the matched group on all sub-tasks was consistently better than that of the mismatched group. The above performance was also achieved in less time than the mismatched group: the mean time taken over the four CBI sessions for the matched group was 265.4 minutes compared to 283.3 minutes for the mismatched group. Hence, it may be plausible to suggest that there might be a pattern (although not significant) in favour of the matched group.

However, while there was no significant difference between the matched and mismatched groups, a significant difference was found to exist between the four learning styles: $\mathrm{F}(3,119)=4.450, \mathrm{p}<.05$. In considering the mean scores of each cognitive style, it is evident that the Wholist/Verbalizer group performed better than all other groups. There was no significant interaction between the different cognitive styles and the matched and mismatched treatments: $F(3,119)=0.979, p<.05$. 


\begin{tabular}{|c|c|c|c|c|c|c|c|c|c|}
\hline & Tota & ecall & $\begin{array}{l}\text { Labell- } \\
\text { ing } \\
\%\end{array}$ & $\begin{array}{l}\text { Explan- } \\
\text { ation } \\
\%\end{array}$ & $\begin{array}{c}\text { Problem } \\
\text { solving } \\
\%\end{array}$ & $\begin{array}{l}\text { Leam } \\
\text { time } \\
\text { min. }\end{array}$ & $\begin{array}{l}\text { Test } \\
\text { time } \\
\text { min. }\end{array}$ & $\begin{array}{l}\text { Total } \\
\text { time } \\
\text { min. }\end{array}$ & $n$ \\
\hline \multicolumn{10}{|c|}{ Matched instructional format } \\
\hline Al & 72.3 & 80.8 & 80.6 & 58.5 & 54.6 & 189.7 & 100.2 & 289.9 & 20 \\
\hline AV & 64.9 & 74.5 & 72.3 & 54.8 & 43.3 & 177.5 & 921 & 269.5 & 20 \\
\hline WI & 67.2 & 77.7 & 77.1 & 49.7 & 48.8 & 148.6 & 77.7 & 226.3 & 15 \\
\hline W & 73.6 & 88.8 & 81.1 & 63.1 & 58.4 & 183.4 & 927 & 276.1 & 12 \\
\hline Total & 69.2 & 79.0 & 77.4 & 56.3 & 50.6 & 175.7 & 91.4 & 265.4 & 67 \\
\hline \multicolumn{10}{|c|}{ Mismatched instructional format } \\
\hline Al & 67.6 & 79.0 & 77.8 & 50.5 & 49.8 & 200.5 & 1023 & 302.8 & 21 \\
\hline AV & 64.3 & 77.7 & 72.9 & 48.5 & 41.3 & 164.6 & 104.5 & 269.1 & 15 \\
\hline WI & 56.2 & 63.4 & 63.0 & 47.4 & 36.2 & 180.3 & 100.3 & 280.6 & 16 \\
\hline w & 73.2 & 79.6 & 82.0 & 60.1 & 45.6 & 1824 & 98.4 & 280.8 & 8 \\
\hline Total 64.5 & 74.9 & 73.2 & 50.5 & 43.5 & 1820 & 101.8 & 283.3 & 60 & \\
\hline
\end{tabular}

Table 2: Mean percentage score on test tasks, learning time, test time and total time for the four cognitive styles

An analysis of the effect of cognitive learning styles on each test task is summarized in Table 2. A one-way analysis of variance indicated a significant difference between the styles on recall: $F(3,126)=3.659, p<.05$; labelling: $F(3,126)=3.628, p<.05$; and explanation: $F(3,126)=3.438, p<.05$. The difference was not significant on problem solving: $F(3,126)=2.58, p<.05$. It appears that certain test tasks were favoured by certain cognitive styles. Considering the mean scores of each cognitive style, it is evident that the Wholist/Verbalizer group performed best on the test tasks followed by the Analytic/Imager group.

\section{Discussion}

The lack of any significant difference between the matched and mismatched groups may be due to a combination of factors. In the second study, it is plausible to argue that the lecture sessions presented just prior to the CBI experiment could have influenced the result. The experimental design allowed no control over the lecture session which was necessary for the course requirements stipulated by the University. The other consideration in both the studies was the need not to make the instructional material too different as it would open social-justice debates within the University. It would have been better if a whole non-credit course could have been identified so that the problems of assessment and equity did not limit the design of instructional material. Perhaps a more robust design dealing with complete topics rather than part of a topic, free of policy implications and using multimedia (audio, video, text, diagrams), would result in larger differences between the matched and mismatched groups, so reaching significant levels. Support for the above can be seen in Liu and Reed (1994) who argue that hypermedia learning environments may greatly enhance the potential to accommodate individual learning preferences. Nevertheless, the results of each sub-task consistently showed enhanced performance by the matched group which also achieved this in less time. This suggests potential for further investigation. 
As noted by Riding and Douglas (1993), the manner in which we perceive and process information can be influenced by the subject content. The subject, Digital Communications, required students not only to understand the details involved in each of the four topics, but also to have an overview of how the details fit together within each topic and with other topics. Similar requirements were noted in Study 1, where explanation was emphasized. Both subject contents sought relational understanding. Such learning facilitates the transfer of knowledge to applications, which is what the problem-solving task in this study tested. The results suggest that Wholist/Verbalizers performed better than the other cognitive styles. This perhaps is due to the advance organizers being presented as a single unit of information which assisted students in reading the detailed explanations and in making relational links between concepts and prior knowledge. The explanatory value of the diagrams used in the Imager instruction must have been low (Mayer and Gallini, 1990). The subject content required students to be able to identify the various components, understand their functions, and reason through the protocol necessary to design systems. Thus the findings of this study, to some extent, support the argument put forward by Riding and Douglas (1993) that subject types have an affinity with certain cognitive styles, and acknowledge the need to consider the nature of the subject matter in designing personalized CBI instruction.

The analysis of test tasks showed a significant difference between the cognitive style groups and the test tasks, suggesting that certain cognitive styles may suit certain types of test tasks. This result was consistent in both the studies. The finding is also consistent with the argument of Riding and Calvey (1981) that the effect of cognitive style on performance depends on the nature of the task. On recall tasks, the Wholist/Verbalizers and Analyticl Imagers did better than Wholist/Imagers and Analytic/Verbalizers. This may be because the recall tasks required words which connected parts of information to the overall concepts. Such words are easily recognized where the instruction provides opportunities to see the overall concept as well as the details as found in Wholist/Verbalizers and Analytic/Imagers. The Wholist/Verbalizers and the Analytic/Imagers, in fact, consistently performed better than the other groups. This may be due to the design of the instructional material which influenced the type of learning outcomes desired (analytic/quantitative or wholist/qualitative). The design of the problem task also favoured the Wholist/Verbalizers because it concentrated on verbal answers and those that required an overall understanding rather than any detailed analysis.

\section{Conclusion}

The studies found that there may be potential for further research in considering personalizing CBI material. The findings also concur with previous findings that subject content may have an affinity with certain cognitive styles. This prompts research into the nature of subject content: what makes a subject more or less suited to certain cognitive style? Although the CBI in these studies used linear presentation, there are more possibilities to improve the CBI material such as the use of voice which may assist the Verbalizers, animations which may help the Imagers, and hotspots for Analytics who may wish to seek detailed information. The design of many CBI materials can benefit greatly by considering the needs for personal learning styles. 


\section{Acknowledgements}

The above studies were made possible by support from Queensland. University of Technology's research programmes. The first study was funded through a Faculty of Education grant to Dr H. Pillay, and the second study through QUT meritorious grants to Dr H. Pillay and Dr W. Boles.

\section{References}

Ambron, S. and Hooper, K. (eds.) (1990), Learning with Interactive Media: Developing and Using Tools in Education, Washington: Microsoft Press.

Ausubel, D.P. (1960), 'The use of advance organizers in the learning and retention of meaningful verbal material', Journal of Educational Psychology, 51, 267-72.

Bork, A. (1991), 'Computers and educational systems', Australian Educational Computing, Journal of the Australian Council for Computers in Education, 6 (2), 34-7.

Borg, M.G. and Riding, R.J. (1993), 'Teacher stress and cognitive style', British Journal of Educational Psychology, 63, 271-86.

Chi, M.T.H., Feltovich, P.J. and Glaser, R. (1981), 'Categorisation and representation of physics problems by experts and novices', Cognitive Science, 5, 121-52.

Claxton, C. and Murrell, P.H. (1987), Learning styles implications for improving educational practices, Washington: Association for the Study of Higher Education.

Dunn, R., Dunn, K. and Price, G.E. (1985), Learning Styles Inventory, London: Lawrence Price Systems.

Entwistle, N. (1981), Styles of Learning and Teaching, Chichester: Wiley.

Farrow, M. (1993), 'Knowledge engineering using Hypercard: a learning strategy for tertiary students', Journal of Computer Based Education, 20 (1), 9-14.

Halford, G. (1993), Children's Understanding: Development of Mental Models, New Jersey: LEA.

Hedberg, J.G., Harper, B. and Brown, C. (1993), 'Reducing cognitive load in multimedia navigation', The Australian Journal of Educational Technology, 9, 157-81.

Jonassen, D.H. (1989), 'Mapping the structure of research and theory in instructional systems technology', Educational Technology, 29 (5), 7-10.

Keefe, J.W. (1979), 'Learning style: an overview' in Keefe, J.W. (ed), Student learning styles: Diagnosing and prescribing programs, Reston: National Association of Secondary School Principals.

Keppel, G. (1991), Design and Analysis: A Researcher's Handbook, 3rd edition, New Jersey: Prentice-Hall.

Kozma, R.B. (1994), 'Will media influence learning? Reframing the debate', Educational Technology, Research and Development, 42 (2), 7-19.

Liu, M. and Reed, M. (1994), 'The relationship between the learning strategies and learning styles in a hypermedia environment', Computers in Human Behaviour, 10, 419-34. 
Mayer, R.E. and Gallini, J.K. (1990), 'When is an illustration worth ten thousand words?', Journal of Educational Psychology, 82 (4), 715-26.

Pillay, H. and Wilss, L. (1996), 'Computer-assisted learning and individual cognitive style preference in learning: does it matter?', Educational Computing, 11 (2), 28-33.

Reeves, T.C. (1993), 'Pseudoscience in computer-based instruction: the case of learner control research', Journal of Computer-Based Instruction, 20 (2), 39-46.

Riding, R.J. and Caine, T. (1993), 'Cognitive style and GCSE performance in Mathematics, English Language and French', Educational Psychology, 13 (1), 59-67.

Riding, R.J. and Calvey, I. (1981), 'The assessment of verbal-imagery learning styles and their effect on the recall of concrete and abstract prose passages by eleven-year-old children', British Journal of Psychology, 72, 59-64.

Riding, R.J. and Cheema, I. (1991), 'Cognitive styles: an overview and integration', Educational Psychology, 11, 193-215.

Riding, R.J. and Douglas, G. (1993), 'The effect of cognitive style and mode of presentation on learning', British Journal of Educational Psychology, 63, 297-307.

Riding, R.J. and Dyer, V.A. (1980), 'The relationship between extraversion and verbalimagery learning style in twelve-year-old children', Personality and Individual Difference, 1 , 273-9.

Riding, R.J., Glass, A. and Douglas, G. (1993), 'Individual differences in thinking: cognitive and neurophysiological perspectives', Educational Psychology, 13, 267-70.

Riding, R.J. and Mathias, D. (1991), 'Cognitive styles and preferred learning mode, reading attainment and cognitive ability in 11 year old children', Educational Psychology, 11, 383-93.

Riding, R.J. and Sadler-Smith, E. (1992), 'Type of instructional material, cognitive style and learning performance', Educational Studies, 18, 323-40.

Rush, G.M. and Moore, D.M (1991), 'Effect of restructuring training and cognitive style', Educational Psychology, 11 (3), 309-21.

Satterly, D.J. and Telfer, I.G. (1979), 'Cognitive style and advance organizer in learning and retention', British Journal of Educational Psychology, 49, 169-78.

Shuell, T.J. (1988), 'The role of the student in learning from instruction', Contemporary Educational Psychology, 13 (3), 276-95.

Sweller, J. (1989), 'Cognitive technology: some procedures for facilitating learning and problem-solving in Maths and Science', Journal of Educational Psychology, 81, 457-66.

Upitis, R. (1990), 'Real and contrived uses of electronic mail in elementary schools', Computers and Education, 15 (3), 233-43.

Witkin, H.A., Moore, C.A., Goodenough, D.R. and Cox, P.W. (1977), 'Field-dependent and field-independent cognitive styles and their educational implications', Review of Educational Research, 47, 1-64. 